\title{
M 変換を用いる高精度表面計測信号中のインパルス状雑音の除去*
}

\author{
原田博 之*1, 柏木濶*2, 安藤 俊 之*3 \\ 大 㴊 慶 史 ${ }^{* 4}$, 椛一 喜*5

\section{Reduction of Impulsive Noise Included in High-Accuracy Surface Measurement Signal by Using M-Transform} \\ Hiroshi HARADA*6, Hiroshi KASHIWAGI, Toshiyuki ANDO, \\ Yoshifumi OHBUCHI and Kazuki KABA \\ ${ }^{* 6}$ Department of Mechanical Engineering and Materials Science, Kumamoto University, \\ 2-39-1 Kurokami, Kumamoto-shi, Kumamoto, 860-8555 Japan

\begin{abstract}
The authors have recently proposed a new signal processing technique called M-transform. In this paper, we propose to use the $\mathrm{M}$-transform for impulsive noise reduction. Since $\mathrm{M}$-transform of a time signal is equivalent to calculate cross-correlation function between the time signal and $\mathrm{M}^{-}$ sequence, both impulsive noise and white noise are converted into small-amplitude random signal through the M-transform. These small-amplitude random signals can be removed by use of some non-linear filter. And then, the filtered signal is transformed into time domain through the inverse $\mathrm{M}$-transform and the noise reduction procedure is completed. The proposed filtering technique is applied to reduce impulsive noise included in surface tracing signal measured by an atomic force microscope. From the results of the experiment, it is shown that the proposed works quite well for impulsive noise reduction.
\end{abstract}

Key Words: Shape Measurement, Information Processing and Signal Analysis, M-Sequence, Correlation Function, Nonlinear Filter

\section{1 、 まえがき}

筆者等は $\mathrm{M}$ 系列信号をもとにした新たな信号の変 換である $\mathrm{M}$ 変換を提案し，その性質および線形系の 同定への応用について述べた ${ }^{(1)}$. さらに, M 変換の 性質を利用して信号に含まれるインパルス状雑音およ び白色雑音を除去する方法を提案した ${ }^{(2)}$. 信号中に 含まれる雑音の除去に関しては, 従来, 様々なフィル 夕が提案されているが, インパルス状雑音および白色 雑音の両方を良好に除去するものは数少ない ${ }^{(3)}$. 本 研究は，この $\mathrm{M}$ 変換を用いる雑音除去手法を高精度 表面計測信号に含まれるインパルス状雑音の除去に適 用したものである.

3 次元表面粗さ測定器, 原子間力影微鏡 (Atomic Force Microscope, AFM) やレーザ䫓微鏡に代表され る高精度表面形状計測においては, 被測定表面の性状 に応じた測定パラメータの設定が比較的難しく, パラ

* 原稿受付 2003 年 8 月 4 日.

*1 正員, 熊本大学工学部知能生産システム工学科( 『 860-8555 熊本市黑髪 2-39-1).

*2 熊本大学工学部知能生産システム工学科

*3 正員, 熊本大学大学院自然科学研究科.

*4 正員, 福岡工業大学工学部知能機械工学科(811-0295 福 岡市東区和白東 3-30-1).

*5 (財)くまもとテクノ産業財団( 益城町田原 2081-10)

E-mail : hiroshi@ mech.kumamoto-u.ac.jp
メー夕設定が適切でない場合や被測定面内の不純物の 存在などにより測定信号にインパルス状の雑音を生じ ることがある.このようなインパルス状雑音の除去は 難しく，また，不適切なフィルタなどにより除去を行 うと本来の形状を丕ませてしまい，正確な形状測定が 困難になる.

本論文ではまず, 文献 (1) で提案された $\mathrm{M}$ 変換に ついて簡単にふれる。 つぎに，新たに提案する $\mathrm{M}$ 変 換による雑音除去方法について述べる. さらに，提案 する方法が有効であることをシミュレーションにより 確認する. 実際に提案する方法を原子間力顕微鏡の信 号に適用し，信号中に含まれるインパルス状雑音の除 去に有効であることを示す.

\section{2. $\mathrm{M}$ 変換とその性質}

筆者等が文献 (1) で提案した $\mathrm{M}$ 変換は以下のよう な信号処理手法である. カロロ体 $G F(2)$ 上で定義さ れた $n$ 次原始多項式 $f(x)$ より発生した $M$ 系列信号 を $\left\{a_{i}\right\}$ とし， \pm 1 の 2 值をとる新たな系列 $\left\{m_{i}\right\}$ を式 (1) のように定義すると, その自己相関関数 $\phi_{m m}(k)$ 
は式 (2) で与えられる ${ }^{(4)}$.

$$
\begin{aligned}
m_{i} & =(-1)^{a_{i}} \\
\phi_{m m}(k) & =\frac{1}{N} \sum_{i=0}^{N-1} m_{i-k} m_{i} \\
& =\left\{\begin{array}{cc}
1 & (k=0, N, 2 N, \cdots) \\
-\frac{1}{N} & \text { (otherwise) }
\end{array}\right.
\end{aligned}
$$

ここで, $N=2^{n}-1$ は $n$ 次 $\mathrm{M}$ 系列の周期である. この式 (2) は $\mathrm{M}$ 系列の擬似直交性 ${ }^{(1)}$ と呼ばれる性 質である.

$\mathrm{M}$ 変換は, この 2 值系列 $\left\{m_{i}\right\}$ を用いて以下のよう に定義できる. まず， 2 值系列 $\left\{m_{i}\right\}$ を用いて $N \times N$ の行列 $M_{i}$ を式 (3) のように構成する.

$$
\boldsymbol{M}_{i}=\left[\begin{array}{cccc}
m_{i} & m_{i-1} & \ldots & m_{i-N+1} \\
m_{i+1} & m_{i} & \ldots & m_{i-N+2} \\
\vdots & \vdots & \ddots & \vdots \\
m_{i+N-1} & m_{i+N-2} & \ldots & m_{i}
\end{array}\right]
$$

つぎに, 時間信号 $x(t)$ を一定のサンプリング間隔 $\Delta t$ おきにサンプルした時系列信号を $x(i \Delta t)$ とし, これ を $x(i)$ と略記して時間信号 $\boldsymbol{X}$ を式 (4) のように定 義する.

$$
\boldsymbol{X}=(x(0), x(1), \cdots, x(N-1))^{T}
$$

このとき, 時系列信号 $\left\{x_{i}\right\}$ の M 変換 $\boldsymbol{A}$ は式 (5) に より定義され, 式 (6) により一意に決定される ${ }^{(1)}$.

$$
\begin{aligned}
\boldsymbol{X} & =\boldsymbol{M}_{\boldsymbol{i}} \boldsymbol{A} \\
\boldsymbol{A} & =\left(\alpha_{0}, \alpha_{1}, \cdots, \alpha_{N-1}\right)^{\boldsymbol{T}} \\
& =\boldsymbol{M}_{\boldsymbol{i}}^{-1} \boldsymbol{X}
\end{aligned}
$$

また, $\mathrm{M}$ 系列信号 $\left\{m_{i}\right\}$ と時間信号 $\left\{x_{i}\right\}$ の相互相 関関数 $\phi_{m x}(k)$ は M 変換 $\boldsymbol{A}$ を用いて式 (7) のよう に表される ${ }^{(1)}$.

$$
\phi_{m x}(k)=\frac{N+1}{N} \alpha_{k}-\frac{1}{N} \sum_{l=0}^{N-1} \alpha_{l}
$$

\section{3. $\mathrm{M}$ 変換を用いる雑音除去法}

本研究では, 前述の $\mathrm{M}$ 変換を用いてインパルス状 雑音と白色雑音の両方を除去する方法を提案する. ま ず, インパルス状信号と白色雑音の $\mathrm{M}$ 変換を考える. 単一インパルスからなるインパルス状雑音 $\boldsymbol{P}_{j}$ を式 (8)のように表す.

$$
\boldsymbol{P}_{j}=\left(0,0, \ldots, p_{j}, 0 \ldots, 0\right)^{T}
$$

ここで, $p_{j}$ はインパルス状雑音の大きさ,$j$ はイン パルスの位置を表す. インパルス状雑音 $\boldsymbol{P}_{j}$ の $\mathrm{M}$ 変
換 $\boldsymbol{A}_{p}$ の要素 $\alpha_{i}$ は式 (6), (8) より, 次式のように表 される.

$$
\alpha_{i}=\frac{1}{N+1}\left(m_{i+j}-1\right) p_{j}
$$

式 (9) より, インパルス状雑音に $\mathrm{M}$ 変換をほどこす ことにより，これを小振幅の $\mathrm{M}$ 系列信号に変換する ことができることがわかる. 一方, 式 (7) より明らか なように, $\mathrm{M}$ 変換は時系列信号と $\mathrm{M}$ 系列信号の相 互相関関数を求めることと等価である. したがって, $\mathrm{M}$ 系列信号と無相関である白色雑音の $\mathrm{M}$ 変換は, 小 振幅の不規則信号となる. 上記の結果より，M 変換を 行うことにより，インパルス雑音と白色雑音はいずれ も小振幅の不規則信号に変換されることがわかる.こ の不規則信号を小振幅雑音の除去に有効な非線形フィ ルタ, 例えば, $\varepsilon$ - 分離非線形フィルタ ${ }^{(5)}$ などを用 いることにより信号中の除去が可能となる．筆者等は 提案する方法により 1 次元信号においてインパルス 状雑音および白色雑音の除去が可能であることを示し た ${ }^{(2)}$. 本論文では雑音除去の対象となる信号が 2 次 元の画像信号であるため, 文献 (5) の方法をもとに, 以下のような 2 つの雑音除去方法を提案する.

まず, 雑音除去の対象となる $N_{1} \times N_{2}$ の 2 次元信 号を $x(i, j)\left(0 \leq i \leq N_{1}-1,0 \leq j \leq N_{2}-1\right)$ とする.

第一の方法 (以下, 方法 A と呼ぶ) では図 1 に示 すように, 2 次元信号 $x(i, j)$ の各列を取り出し, 式 (10) のように 1 次元信号 $\boldsymbol{X}_{j}\left(0 \leq j \leq N_{1}-1\right)$ と する.

$$
\boldsymbol{X}_{j}=\left(x(0, j), x(1, j), \cdots, x\left(N_{2}-1, j\right)\right)^{T}
$$

この場合, $n$ 次 $\mathrm{M}$ 系列信号を用いて $\mathrm{M}$ 変換を行う ため, 画像の大きさは $N_{2}=2^{n}-1$ を満足する必要 がある. この 1 次元信号 $\boldsymbol{X}_{j}$ の M 変換 $\boldsymbol{A}_{j}(0 \leq j \leq$ $\left.N_{1}-1\right)$ は式 (11) より求められる.

$$
\boldsymbol{A}_{j}=\left(\alpha_{0}, \alpha_{1}, \cdots, \alpha_{N_{2}-1}\right)^{T}
$$

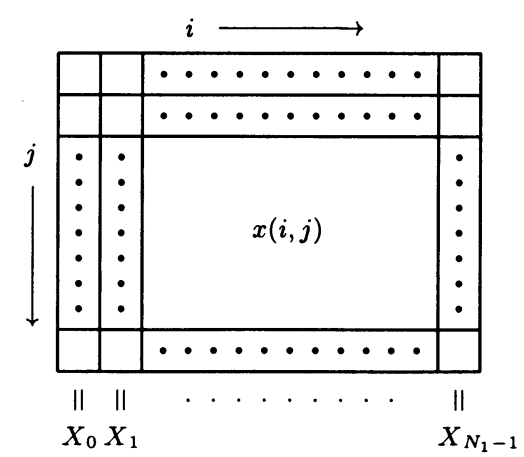

Fig. 1 Construction of one-dimensional signal in case of method A 


$$
=M_{i}^{-1} X_{j}
$$

得られた $\mathrm{M}$ 変換 $\boldsymbol{A}_{j}$ を小振幅雑音を除去する非線形 フィルタに通す．非線形フィルタを通した後の $\mathrm{M}$ 変 換 $B_{j}$ を式 (12) のようにおくと，その要素 $\beta_{i}$ はも との M 変換 $\boldsymbol{A}_{j}$ の要素を用いて式 (13) のように表 すことができる.

$$
\begin{gathered}
\boldsymbol{B}_{j}=\left(\beta_{0}, \beta_{1}, \cdots, \beta_{N_{2}-1}\right)^{T} \\
\beta_{i}=g\left(\alpha_{i-L}, \alpha_{i-L+1}, \cdots, \alpha_{i}\right)
\end{gathered}
$$

ここで, $g$ は非線形な関数であり， $L$ は非線形フィ ルタのフィルタ長である. たとえば，小振幅雑音の除 去に有効な非線形フィルタである $\varepsilon-$ 分離フィルタ ${ }^{(5)}$ の場合， $B_{j}$ の各要素は式 (14)により求められる.

$$
\beta_{i}=\alpha_{i, j}-\sum_{l=0}^{L-1} a_{l} \cdot h\left(\alpha_{i, j}-\alpha_{i-l, j}\right)
$$

式 (14)において, $a_{l}$ は定数, 関数 $h$ は

$$
|h(x)| \leq \varepsilon \quad(\varepsilon: \text { 正の定数 })
$$

を満足する非線形関数である. 非線形フィル夕を通し た $\mathrm{M}$ 変換 $\boldsymbol{B}_{j}$ を式 (5) に代入し, 逆 $\mathrm{M}$ 変換するこ とにより, 雑音が除去された信号が得られる.この処 理を画像信号の各列について行うことにより，雑音が 除去された 2 次元信号 $x_{f}(i, j)$ が得られる.

第二の方法 (以下, 方法 B ट呼ぶ) では, まず, 前述 の方法 A により, 雑音を除去した 2 次元信号 $\xi_{f}(i, j)$ を求める.つぎに，図 2 に示すように，もとの 2 次 元信号 $x(i, j)$ の各行より式 (16) にしたがって 1 次 元信号 $\boldsymbol{Y}_{i}\left(0 \leq i \leq N_{2}-1\right)$ を作成する.

$$
\boldsymbol{Y}_{i}=\left(x(i, 0), x(i, 1), \cdots, x\left(i, N_{1}-1\right)\right)^{T}
$$

このとき, $n$ 次 $\mathrm{M}$ 系列信号を用いて $\mathrm{M}$ 変換を行う ため, 画像の大きさは $N_{2}=2^{n}-1$ を満足する必要

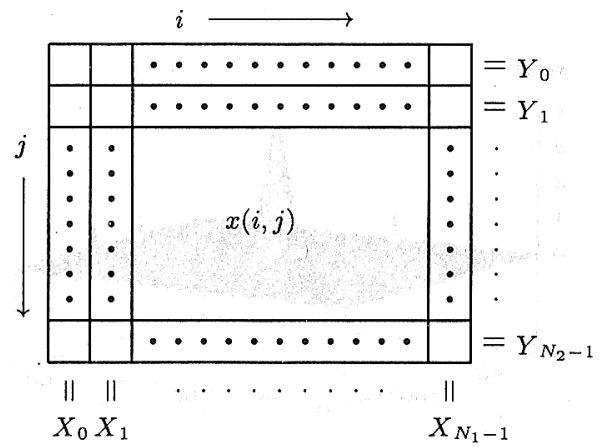

Fig. 2 Construction of one-dimensional signal in case of method B
がある. 方法 $\mathrm{A}$ と同様に，得られた 1 次元信号 $Y_{i}$ の $\mathrm{M}$ 変換を非線形フィルタを通して小振幅雑音を除 去した信号を逆 M 変換することにより, 雑音を除去 した 2 次元信号 $\eta(i, j)$ が求まる. もとの 2 次元信 号 $x(i, j)$ より式 $(17)$ にしたがって, 得られた信号 $\xi(i, j)$ および $\eta(i, j)$ のうち絶対值の小さなものを信 号の值 $x_{f}(i, j)$ とするという方法である.

$$
x_{f}(i, j)= \begin{cases}\xi(i, j) & \text { if }|\xi(i, j)| \leq|\eta(i, j)|) \\ \eta(i, j) & \text { (if }|\xi(i, j)>| \eta(i, j) \mid)\end{cases}
$$

次章のシミュレーション結果にも示すように，第一の 方法 $\mathrm{A}$ ではインパルス状雑音が十分に除去されてない 場合でも方法 B を用いることにより, 雑音の少ない 信号が得られる。

\section{4. シミュレーション結果}

提案した方法によりインパルス状雑音と白色雑音の 除去が可能であることを確認するため，以下のように シミュレーションを行った。 まず, もとの 2 次元信 号 $x_{o}(i, j)(0 \leq i \leq 126,0 \leq j \leq 126)$ が式 (18) で表 されるような 2 次元ガウス信号の場合を考える.

$$
\begin{gathered}
x_{o}(i, j)=\frac{A}{\sqrt{2 \pi} \sigma} \exp \left\{\frac{(i-\mu)^{2}+(j-\mu)^{2}}{2 \sigma^{2}}\right\} \\
A=40.0, \quad \mu=63.0, \quad \sigma=4.0
\end{gathered}
$$

もとの 2 次元信号 $x_{o}(i, j)$ に 10 個のインパルス雑 音および区間 $[-0.1,0.1]$ で一様に分布する白色雑音 を付加した 2 次元信号 $\{x(i, j)\}$ を図 3 に示す. 図 3 にしめした雑音を含む 2 次元信号よりインパルス雑 音を含む列 $x\left(i, j_{p}\right)$ を取り出したものを図 4 に示す. また，図 5 は図 4 に示した信号に対して式 (6) によ

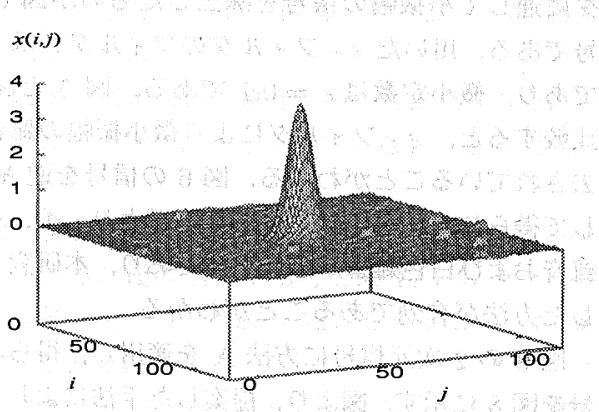

Fig. 3 Original signal $x(i, j)$ which includes impulsive noise and white noise 


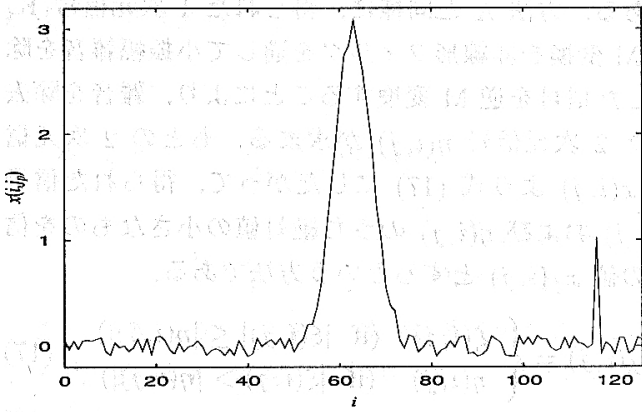

Fig. 4 Original signal $x\left(i, j_{p}\right)$ including impulsive noise

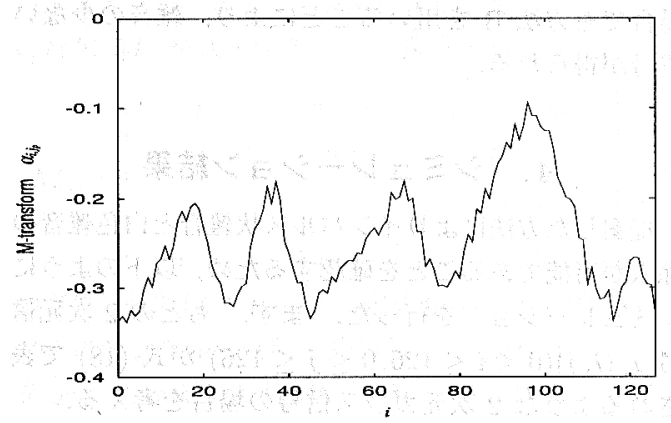

Fig. 5 M-transform of the original signal

り求めた $\mathrm{M}$ 変換である.ここで, 信号 $x\left(i, j_{p}\right)$ の長 さが $N=127$ であるため， $\mathrm{M}$ 変換には特性多項式 $f(x)$ が次式で表されるような次数 $n=7$ の 系列 信号を用いている

$$
f(x)=x^{7}+x^{3}+1
$$

図 5 より, 得られた $\mathrm{M}$ 変換がもとの信号の $\mathrm{M}$ 変換 である振幅の大きな信号とインパルス状雑音および 白色雑音の $\mathrm{M}$ 変換である微小振幅の不規則信号から

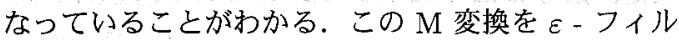
夕に通して小振幅の信号を除去したものが図 6 の信 号である. 用いた $\varepsilon-$ フィルタのフィルタ長は $L=5$ であり，微小定数は $\varepsilon=0.1$ である，図 5 と図 6 を 比較すると, $\varepsilon$ - フィル夕により微小振幅の雑音が除 去されていることがわかる. 図 6 の信号を逆 $\mathrm{M}$ 変換 して得られた信号を図7に示す. 図より,インパルス 雑音および白色雑音が除去されており, 本研究で提案 した方法が有効であることがあかる。

図 3 の 2 次元信号に方法 $\mathrm{A}$ を適用し，得られた信 号を図 8 に示す. 図より，提案した手法によりインパ ルス状雑音と白色雑音が除去されているのがわかる. しかし，インパルス状雑音の影響が少し残っている.

一方，図 9 は図 3 の信号に対して，方法 Bにより 雑音除去を行った結果である. 図 8,9 を比較すると,

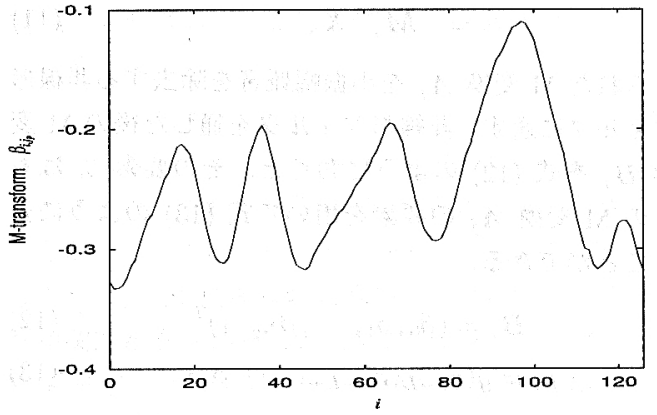

Fig. 6 Filtered M-transform

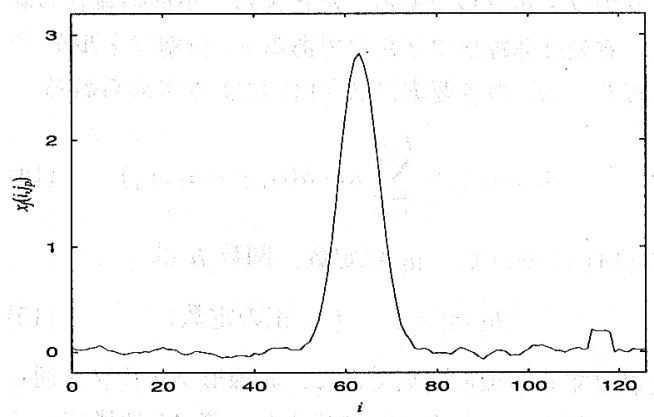

Fig. 7 Reconstructed signal $x_{f}\left(i, j_{p}\right)$

方法 B の方がインパルス状雑音および白色雑音をよ く除去されていることは明らかである.

つぎに，提案する手法の有効性を式 (20) により定 義した平均 2 乗誤差 (MSE) を用いて定量的に評価 Lた.

$$
\mathrm{MSE}=\sum_{i=0}^{N_{1}-1} \sum_{j=0}^{N_{2}-1}\left(x_{f}(i, j)-x_{o}(i, j)\right)^{2}
$$

式 $(20)$ において $x_{o}(i, j), x_{f}(i, j)$ はそれぞれ, もとの 2 次元信号および雑音を除去したあとの信号である. MSE と雑音除去に用いるフィルタ長 $L$ の関係を求め

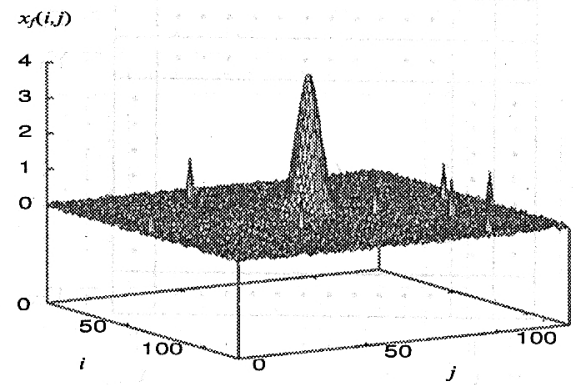

Fig. 8 Signal $x_{f}(i, j)$ reconstructed by method A 


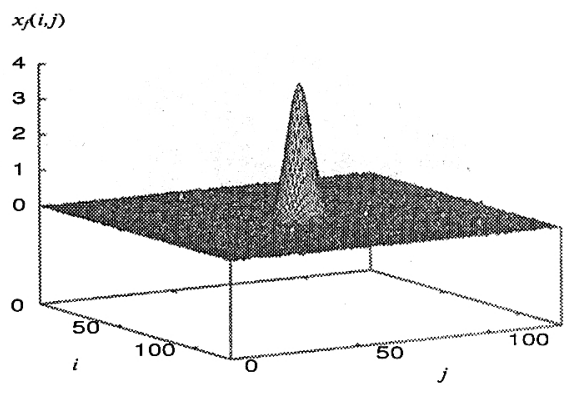

Fig. 9 Signal $x_{f}(i, j)$ reconstructed by method B

た結果が図 10 である.ここで，雑音除去の対象とし た信号は図 3 と同様の 2 次元ガウス信号 $x_{o}(i, j)$ に 10 個のインパルス状雑音と白色雑音を付加した信号 である. 方法 B は $\mathrm{M}$ 変換とともに用いる非線形フィ ルタは図 8 の場合と同様に $\varepsilon$ - 分離フィルタである. また比較の対象として, 線形フィルタであるフィルタ 長 $L$ の平均值フィルタを用いた場合の MSE も図中 にプロットしている，図より，提案する方法 B では, 線形フィルタを用いた場合よりも MSE の值が小さく， 雑音低減に有効であることがわかる。一般にフィルタ を用いて雑音を除去する場合, フィルタ長が長くなる 之雑音除去後の信号の形状が変化し，誤差が大きくな る.これに対して，提案する力法は短いフィルタ長ば あいでも雑音低減の効果が大きいことがわかる，図が わかりにくくなるため, 図 10 では方法 A の MSE 值 はプロットしていないが, 方法 A では, フィルタ長 $L$ が短い場合 $(L \leq 9)$ においては線形フィルタとほ ぼ同じ MSE 值を示し，フィルタが長くなると方法 B と同じ MSE 值をとる. 以上の結果より，本研究で提 案した方法においては，方法 B において短いフィル

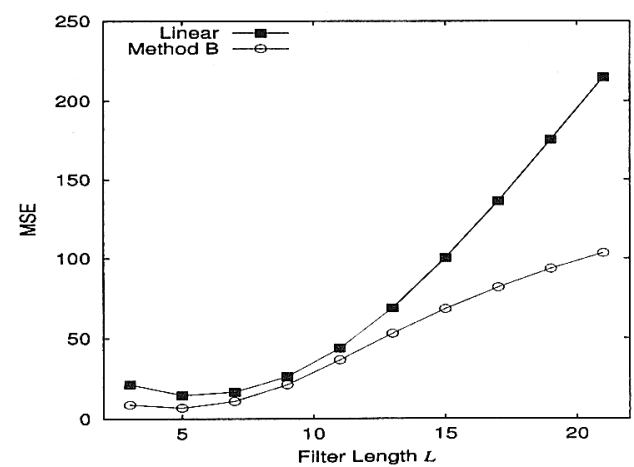

Fig. 10 Relation between filter length $L$ and MSE
夕長の非線形フィル夕を使用することが雑音低減に有 効であると考えられる.

\section{AFM 信号中の雑音除去}

本論文では, 前章で提案した雑音除去方法を超精 密表面形状計測機器のひとつである原子間力顕微鏡 (Atomic Force Microscope, AFM) の信号に含まれる インパルス状雑音の除去に適用した. AFM は原子間 力を用いて物体の表面形状を計測するが, 走査速度 を上げるとインパルス状の雑音が混入し, 正確な測定 が困難になる.このようなインパルス状雑音は通常の ガウシアンローパスフィルタやメディアンフィルタで は十分に雑音を除去することができない ${ }^{(6)}$.このた め, 局所的なメディアンフィルタなどが提案されてい る ${ }^{(6)}$ が, 近傍領域の選び方が不適当な場合, この方 法でもインパルス状雑音や白色雑音が十分に除去でき ない。

本研究では, 前章で提案した $\mathrm{M}$ 変換を用いる雑音 除去手法を原子間力顕微鏡信号中の雑音除去に用い る. 本研究で使用した原子間力顕微鏡はセイコー電 子工業㮫 SPI3700 であり, 測定範囲は最大で $150 \mu \mathrm{m}$ $\times 150 \mu \mathrm{m}$, 最小で $1 \mu \mathrm{m} \times 1 \mu \mathrm{m}$ である. 変位検出分 解能は測定範囲が $1 \mu \mathrm{m} \times 1 \mu \mathrm{m}$ 場合に最小であり, 面 内が $0.2 \mathrm{~nm}$, 垂直方向が $10^{-2} \mathrm{~nm}$ である. AFM チップは底辺が $4 \mu \mathrm{m}$ の四角錐形状の窒化理素であ り, 先端半径は充分に小さく, また摩耗により分解能 の低下が生じれば直ちに交換する消耗品であるため, 分解能の值への影響はない.

図 11 にインパルス状雑音を含んだ AFM 信号の一 例を示す。ここで, 測定に使用した試料は半導体デバ イス用に鏡面研磨したシリコンである。走查速度は $1 \mathrm{~Hz}$, 測定範囲は $25.57 \mu \mathrm{m} \times 25.57 \mu \mathrm{m}$ であり, 図は 測定した $256 \times 256$ 画素の画像より $127 \times 127$ 画素 を取り出し, 表示したものである. 図より, この画像 信号にはインパルス状の雑音が多く含まれており, 試 料の正確な表面性状は測定できていないことは明らか である.

この画像信号に対して, 提案する方法 A により雑 音除去を行った後の AFM 信号を図 12 に示す.この 場合, 画像の大きさが $127 \times 127$ であるため, M 変 換に使用した $\mathrm{M}$ 系列信号の次数は $n=7$ である. 非 線形フィルタとしては, フィルタ長 $L=5$ の傾斜適応 $\varepsilon$-フィルタ ${ }^{(5)}$ を用いている. 図より, 提案する方法 Aにより，インパルス状雑音が低減されていることが わかるが，まだインパルス状雑音の影響が大きな部分 
$z$ [nm]

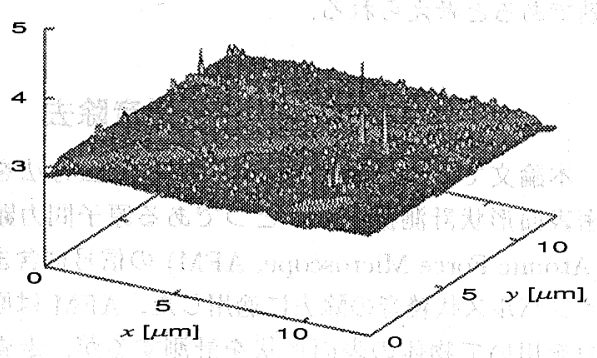

Fig. 11 AFM signal including impulsive noise

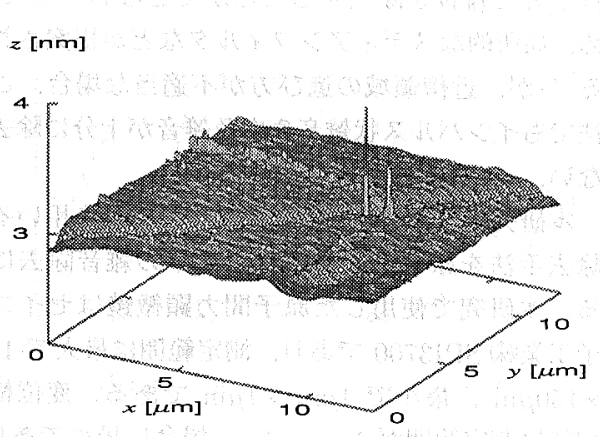

Fig. 12 AFM signal reconstructed by method A があり，明暸な物体の表面形状は得られていない。

一方, 図 13 は万法 B により雑音除去処理を行っ た信号である. 図 12 と図 13 を比較すると、インパ ルス状雑音が除去されており, 試料表面の溝状の部分 が明確になっていることがわかる.ただ被測定表面上 の異物に起因すると思われる画像中の特に大きなイン パルス状雑音に関しては，提案する力法でも除去は不 可能であった.

\section{6.あとがき}

本研究では, $\mathrm{M}$ 変換の性質を利用して, 信号に含 $z$ [nm]

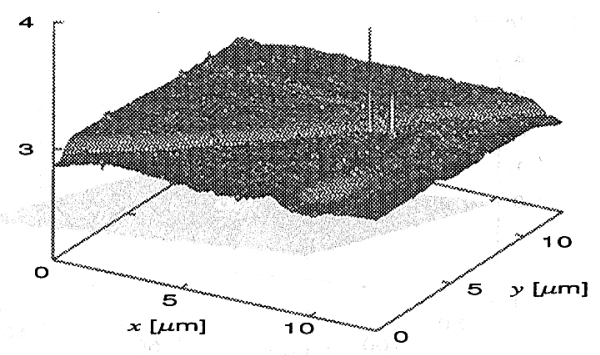

Fig. 13 AFM signal reconstructed by method $B$

まれるインパルス状雑音および白色雑音を除去する新 たな方法を提案した. シミュレーションの結果より, 線形フィルタよりも雑音除去に有効であることが確認 された. さらに，提案する方法を原子間力影微鏡信号 に含まれるインパルス状の雑音の除去に適用し，良好 な結果が得られることを示した. 本論文で提案した雑 音除去方法は $\mathrm{M}$ 変換と様々な非線形フィルタを組み 合わせることにより，高精度表面計測等における種々 の雑音除去に有効であると考えられる.

\section{文 献}

(1) H.Kashiwagi, M.Liu, H.Harada and T.Yamaguchi, $M$-transform and its Application to System Identification, "Trans. of the Society of Instrument and Control Engineers", Vol:E-1, No.1, (2002), pp.289294

(2) 原田, 柏木, 安藤, 椛, $\mathrm{M}$ 変換を用いるインパルス 状雑音除去, ”計測自動制御学会論文集", 39 巻, 7 号, (2003), pp.688-690

(3) 棟安, 田口, 非線形ティジタル信号処理, 朝倉書店 (1999 )

（4）柏木， $M$ 系列とその応用, 昭晃堂, (1996)

(5) 原島, 小田島, 鹿喰, 宮川, $\varepsilon$ - 分離非線形ディジ夕 ルフィルタとその応用, ”電子通信学会誌”, J65-A 巻, 4 号, (1982), pp.297-304

(6) 柳, 成瀨, 光学式表面凹凸形状測定機におけるデー 夕補正の試み, "精密工学会誌”, 67 巻, 1 号, (2001), pp.106-108 